\title{
G4HJ: Moving Forward in 2021
}

\author{
Kimberly Hieftje, PhD
}

I AM DELIGHTED AND HONORED to assume the position of Editor-in-Chief of Games for Health Journal (G4HJ) effective January of this year. As the premier journal in the field of serious games for health, $G 4 H J$ continues to be an important resource and forum for health game researchers, creators, and enthusiasts around the world.

I would like to acknowledge and offer my sincerest thanks to Dr. Tom Baranowski for his outstanding leadership of the journal for the past 7 years, along with his wife and Editorial Coordinator Dr. Janice Baranowski. Dr. Baranowski has been an essential and important voice in the field of games for health and his work has influenced so many researchers, including myself. Even as he transitions into a well-deserved retirement from the field, his passion for games research and the continued success and future of this journal have been apparent in my recent conversations with him.

As a health games researcher for over a decade, I have watched the field evolve in some important and substantial ways. For far too long, the term "health" has often been viewed as being synonymous with "physical health," and has evoked thoughts on topics such as weight management, nutrition, disease prevention and control, and exercise. And although physical health — and should - continues to be an important focus of health games, I believe it is essential that we expand our thinking to consider how other dimensions of health and wellness are being represented in games research. It is my vision for the journal that we, like the field, evolve to include more high-quality research articles concentrated on health topics that extend beyond physical health, and include games that focus on social, emotional, mental, environmental, occupational, and spiritual health, for example.

Just as our view of the term "health" has expanded, we must also consider how the idea of the term "game" has also evolved in our field. Although most health games continue to take on the form of card, board, or video game, we would be remiss if we did not recognize and highlight the exciting work being done in health games research that utilizes in- novative technologies such as artificial intelligence and extended realities (i.e., virtual, augmented, and mixed reality). It is an exciting time to be in our field, and I look forward to seeing more submissions that highlight new approaches to health games.

Finally, I believe that the health games field would benefit from more articles being published in two important, and often overlooked, areas of interest: (1) the processes used by research teams to develop health games, including theoretical approaches to game design and development, and (2) research focused on the implementation of games in their intended settings (i.e., classroom, clinical care, and hospitals). I believe $G 4 H J$ is in an excellent position to become a reputable repository of articles focused on well-established processes for developing impactful games and on approaches to successful implementation of these games.

As Editor-in-Chief I look forward to continuing the great work of Dr. Tom Baranowski and the entire editorial team, including our new editorial board. Although changes to the journal's aims and scope are imminent, so is the journal's growth and evolution within the field. I am confident in our dedicated editorial team, our rigorous peer review process, and our standards for selecting high-quality scientific research articles. As I take on this new role, I look forward to input from our readers to enhance the scope and quality of the journal.

I look forward to your research contributions to the Games for Health Journal!

Address correspondence to:
Kimberly Hieftje, PhD
General Internal Medicine
Yale School of Medicine
2 Church St South Suite 515
New Haven, CT 06510
USA

E-mail: kimberly.hieftje@yale.edu

Director, play4REAL XR Lab; Deputy Director, Yale Center for Health \& Learning Games/play2PREVENT Lab, Yale School of Medicine, New Haven, Connecticut, USA. 